$11-2020$

\title{
Peer-assisted learning (PAL): An innovation aimed at engaged learning for undergraduate medical students
}

\author{
Hasan Salman Siddiqi \\ Aga Khan University, salman.siddiqi@aku.edu \\ Rehana Rehman \\ Aga Khan University, rehana.rehman@aku.edu \\ Farzeen Fatma Syed \\ University Of Liverpool, UK. \\ Russell S. Martins \\ Aga Khan University, russell.martins@scholar.aku.edu \\ Muhammad Talal Ibrahim \\ Aga Khan University, talal.ibrahim@scholar.aku.edu
}

See next page for additional authors

Follow this and additional works at: https://ecommons.aku.edu/pakistan_fhs_mc_bbs

Part of the Life Sciences Commons, and the Medical Education Commons

\section{Recommended Citation}

Siddiqi, H. S., Rehman, R., Syed, F. F., Martins, R. S., Ibrahim, M. T., Alam, F. (2020). Peer-assisted learning (PAL): An innovation aimed at engaged learning for undergraduate medical students. JPMA. The Journal of the Pakistan Medical Association, 70(11), 1996-2000.

Available at: https://ecommons.aku.edu/pakistan_fhs_mc_bbs/892 


\section{Authors}

Hasan Salman Siddiqi, Rehana Rehman, Farzeen Fatma Syed, Russell S. Martins, Muhammad Talal Ibrahim, and Faiza Alam 


\title{
Peer-Assisted Learning (PAL): An innovation aimed at engaged learning for undergraduate medical students
}

\author{
Hasan Salman Siddiqi1, Rehana Rehman², Farzeen Fatma Syed³, Russell Seth Martins4, Muhammad Talal Ibrahim5, Faiza Alam6
}

\begin{abstract}
Objective: To evaluate the effectiveness of Peer Assisted Learning in teaching at undergraduate level and to assess its effects on Peer Leaders and Peer Learners.

Methods: The cross-sectional study was conducted at the Aga Khan University, Karachi, from May to October 2017, and comprised Peer Learners who were trained by faculty members in workshops and pre-run of experiments. Students were divided into two groups; Group A had Peer Learners taught by Peer Leaders, and Group B had those taught by trained lab technologists. Knowledge of the groups was assessed by a quiz using Kahoot. Post-session feedback questionnaires were also filled by the participants. Data was analysed using SPSS 23.

Results: There were 10 Peer Leaders with a mean age of $19.5 \pm 0.85$ years, and 62 Peer Learners with a mean age of $19.08 \pm 0.81$ years. Among the learners, there were 35(56.5\%) males and 27(43.5\%) females. Post-session assessment showed a significant difference in the test performance by the two groups $(p<0.05)$. Feedback indicated that the learners found Peer Leaders more accessible than lab staff, leading to enhanced understanding of the subject.

Conclusion: Peer-Assisted Learning was found to promote learning by creating an informal student-friendly learning environment.
\end{abstract}

Keywords: PAL, Evaluation, Teachers, Experiments.

(JPMA 70: 1996; 2020) DOI: https://doi.org/10.5455/JPMA.29714

\section{Introduction}

The modern trends in medical education require effective improvements in the methods of teaching to provide a better and holistic educational framework. ${ }^{1}$ The roots of Peer-Assisted Learning (PAL) go back as far as the ancient Greeks who thought of the Peer Leader (PL) as a surrogate teacher with whom they could discuss their ideas and concerns. 2,3 The use of PAL has continued through the ages, evolving in its perception and practice. Today, PAL can be defined as an educational model where a group of students, called Peer Learners (PLns), gain knowledge or skills from people of similar social groupings who are not professional teachers; the PLs. PAL can be classified broadly into the same level where both PL and PLns are roughly of the same status, and the cross level where the PL is senior or superior to the PLn. The PLs generally receive training focused on the portion of curriculum that they are required to teach to the PLns.

There are many theories explaining PAL's effectiveness as a teaching method. The idea that cognitive congruence between same-level PLs and PLns fosters greater assimilation of material being taught, is the foundation of PAL. ${ }^{4}$ This makes a better learning environment, with PLns feeling more at ease in terms of asking questions, 5 discussing their ideas and concerns, 6 and volunteering to

1,2,6Department of Biological and Biomedical Sciences, Aga Khan University; 3,4,54th Year Medical Student, Aga Khan University, Karachi, Pakistan.

Correspondence: Faiza Alam e-mail: faiza.orakzai@gmail.com perform tasks. This more relaxed environment is helpful in student learning ${ }^{7}$ and builds a rapport between PLs and PLns. 8

PAL can be beneficial to a medical institution, as it lessens the teaching load on faculty ${ }^{9}$ so that they can focus on research and publications, clinical practice, further training and fulfilment of their professional responsibilities. ${ }^{10}$ Moreover, PAL can also be used to fill gaps in the curriculum taught by professional faculty. ${ }^{11}$ Additionally, PAL is also more economically feasible ${ }^{3}$ compared to conventional teaching methods, which is another advantage. Lastly, the supplementation of professional teaching with PAL would prove to be of enormous value in places that are severely resource-constrained ${ }^{4}$ and lack sufficient professional teachers. A study in South Africa showed that the country had a significantly low ratio of healthcare workers to population due to the recession and consequent emigration of medical professionals from South Africa to other countries. ${ }^{12}$ This adds a huge burden on the teaching staff and PAL's effectiveness is even more pronounced.

Several institutions have practiced PAL and it has been shown to be beneficial to both PLs and PLns. ${ }^{12}$ PAL is currently disseminated across curricula of most medical schools. A 2014 systematic review concluded that "there are many perceived learning benefits for student tutors".8 For learners, the evidence suggests that PAL achievements in terms of performance are predominantly short-term and that these are comparable with those produced by faculty- 
based teaching. ${ }^{13}$ Effectiveness of PAL was also proven to be equivalent to Expert-Assisted Learning (EAL) in a study done in Lahore. ${ }^{14}$

PAL creates a comfortable learning environment, which facilitates learners' confidence and allows them to ask questions without hesitation, which is a feature highly appreciated by PLns.5,8,15 Furthermore, PAL fosters collaboration between students, encouraging them to support and learn cooperatively from one another. ${ }^{5}$ Additionally, apart from the PLns learning the material effectively, the PLs themselves gain knowledge while preparing and teaching for PAL sessions. ${ }^{5}$

Other than imparting academic knowledge, research shows PAL also holds a host of developmental benefits for PLs, such as an increase in confidence and better communication skills. ${ }^{15}$ Skills such as these are useful for the professional careers of individuals. ${ }^{3}$ As the technique of PAL continues to be improved upon, the list of its benefits continues to grow. The current study was planned to introduce PAL in a private medical university at the undergraduate level in order to assess its value and impact.

\section{Subjects and Methods}

The cross-sectional study was conducted from May to October 2017 at Aga Khan University, Karachi. After approval from the institutional ethics review committee, PAL sessions were conducted during the Physiology and Pharmacology laboratory sessions of Year-l batch in its Gastrointestinal Tract Module. PLs were also selected from Year-I. All Year-I students were informed of the PL recruitment process and online applications were then submitted by interested students. All applicants were asked to write a short proposal explaining why they wanted to be a PL. Curriculum Representatives (CRs) and Faculty Members (FMs) with past experience of conducting interviews for such selection processes shortlisted the PLs on the basis of predetermined criteria as well as satisfactory academic performance. No proper formula was adopted. The selected PLs were trained for PAL sessions through a workshop, 16 hands-on sessions and Physiology and Pharmacology lab practical pre-run sessions. FMs and trained lab technologists (LTs) oversaw the training of PLs. For both lab sessions, the batch was divided into two groups. Students who consented to take part in PAL as PLns comprised Group A and were taught by PLs. The remaining students comprised Group B and were taught by trained LTs. In the Pharmacology lab, each PL taught 7-8 PLns, and the LTs taught 9-10 students. In the Physiology lab, each PL taught 11-12 PLns, while LTs taught 6 students each. The formative assessment of
Table-1: Comparison of scores of Pear Learners with students facilitated by trained lab technologists.

\begin{tabular}{|c|c|c|c|c|c|c|c|}
\hline \multirow{2}{*}{$\begin{array}{l}\text { Marks obtained } \\
\text { out of } 5\end{array}$} & \multicolumn{3}{|c|}{ Peer Learners (Group A) } & \multicolumn{3}{|c|}{ Trained lab technologists (Group B) } & \multirow[t]{2}{*}{$p$-value } \\
\hline & Median & Minimum & Maximum & Median & Minimum & Maximum & \\
\hline Physiology Lab & 3.00 & 2.00 & 5.00 & 3.00 & 2.00 & 5.00 & $0.012^{*}$ \\
\hline Pharmacology Lab & 4.00 & 2.00 & 5.00 & 3.00 & 2.00 & 4.00 & $0.0009^{*}$ \\
\hline
\end{tabular}

Mann-Whitney $U$ Test was used to compare rank values. ${ }^{*} p<0.05$ was considered significant. learning in both the sessions was done through a quiz in the form of a post-session test that had multiple choice questions (MCQs) using Kahoot software, and the results of both the groups were compared.

Feedback questionnaires for both PLs and PLns were designed and validated thorugh a pre-test on a group of 10 students. The reliability of the questionnaire was determined to be 0.857 by measuring the related Cronbach's alpha, which was $81 \%$, indicating good consistency in the responses. The PL questionnaire included close-ended and open-ended questions related to skills they gained (no change, improved or definitely improved), problems they faced during the lab sessions and any relevant suggestions they would like to give for improving PAL. The PLn questionnaire evaluated PAL as a teaching strategy on a 5-point Likert scale (strongly disagree to strongly agree), while other questions inquired about the activities and the subject matter taught in the PAL session.

Data from the MCQ test was stored and analysed using SPSS 23. The results of the comparison of scores and the impact of the demographics of the subjects on the lab sessions was analysed using Mann-Whitney $U$ test, while Run test was utilised to obtain the results from the responses acquired regarding the $\mathrm{PAL}$ sessions. $\mathrm{P}<0.05$ was considered significant. Frequency of the responses of both the questionnaires was also analysed for close-ended questions. In the post-PAL feedback form for PLns, the responses under the "strongly agree" category were merged with the responses under "agree", and, similarly, "strongly disagree" and "disagree" were also merged. In post-PAL feedback for PLs, responses under the "improved" and "definitely improved" categories were also merged in oerder to compare them with the "no change" category.

\section{Results}

There were 10 Peer Leaders with a mean age of $19.5 \pm 0.85$ years. There were $5(50 \%)$ PLs in each of the two labs. Initially, there were 94 PLns in Group A and as many controls in Group B who were taught by 12 trained LTs. Of the enrolled PLns, 62(66\%) completed the study. They had a mean age of $19.08 \pm 0.81$ years. Among the learners, there were $35(56.5 \%)$ males and $27(43.5 \%)$ females; $18(29 \%)$ had studied under the Pakistan Higher Secondary Education (HSE) system and 44(71\%) had studied under the 
Table-2: Response acquired from Peer Learners regarding Peer-Assisted Learning (PAL) sessions ( $n=62)$.

\begin{tabular}{lcccc}
\hline Statements & $\begin{array}{c}\text { Strongly Disagree/ } \\
\text { Disagree } \\
\mathbf{n}(\%)\end{array}$ & $\begin{array}{c}\text { Neutral } \\
\mathbf{n}(\%)\end{array}$ & $\begin{array}{c}\text { Agree/ } \\
\text { Strongly Agree } \\
\mathbf{n}(\%)\end{array}$ & p-value \\
\hline The PAL session was appropriately placed in the academic schedule for the module $6(9.7)$ & $22(35.5)$ & $34(54.8)$ & 0.10 \\
The PLs for the PAL session were appropriately selected. & $6(9.7)$ & $10(16.1)$ & $46(74.2)$ & 0.55 \\
The topics taught in the PAL session were appropriately selected. & $4(6.5)$ & $19(30.6)$ & $39(62.9)$ & 0.79 \\
The activities carried out in the PAL session were helpful and appropriate. & $8(12.9)$ & $15(24.2)$ & $39(62.9)$ & 0.26 \\
Prior information about the session was adequately communicated to PLns. & $11(17.7)$ & $17(27.4)$ & $34(54.8)$ & 0.65 \\
You were inspired to attend the PAL session & $33(53.2)$ & $29(46.8)$ & - & N.A \\
\hline
\end{tabular}

Total number of responses $=62$. Responses were acquired by a 5 point Likert scale (strongly disagree to Strongly agree). Strongly agree was merged with Agree to create a positive response whereas negative response was acquired by merging strongly disagree with disagree. Positive and Negative responses were compared by using Run test.

Table-3: Response acquired from Peer Leader Feedback Questionnaire ( $n=10)$.

\begin{tabular}{lcc}
\hline $\begin{array}{l}\text { Skills developed after } \\
\text { PAL experience }\end{array}$ & $\begin{array}{c}\text { Definitely Improved/ Improved } \\
\mathbf{n}(\%)\end{array}$ & $\begin{array}{c}\text { No Change } \\
\mathbf{n}(\%)\end{array}$ \\
\hline Leading/chairing a group & $9(90)$ & $1(10)$ \\
Management skills & $9(90)$ & $1(10)$ \\
Confidence & $10(100)$ & 0 \\
Communication skills & $10(100)$ & 0 \\
Critical thinking skills & $8(80)$ & $2(20)$ \\
Problem solving skills & $6(60)$ & $4(40)$ \\
Presentation \& Teaching skills & $10(100)$ & 0 \\
Ability to adapt to a particular audience & $9(90)$ & $1(10)$ \\
Interpersonal skills & $10(100)$ & 0 \\
Other skills (please specify) - Teamwork, & $9(90)$ & $1(10)$ \\
Delegation, Ability to work under pressure, respect, professionalism. & \\
\hline
\end{tabular}

PAL: Peer-Assisted Learning

Cambridge International Examination Board for Advanced Levels (CIE A-Levels).

Post-PAL MCQ test showed a significant difference in the performance by Group A compared to Group B (Table 1).

In feedback, 46(74.2\%) PLns agreed that PLs were chosen appropriately for the PAL session, while 39(62.9\%) agreed that the topics taught, and the activities carried out in the PAL session were appropriately selected. Before the PAL session, none of the PLns were actually looking forward to it; $33(53.2 \%)$ were negative and $29(46.8 \%)$ were neutral about the idea (Table 2).

In their feedback, all the 10(100\%) PLs were extremely satisfied with the experience, and agreed with the notion that PAL has the potential for developing the personality and character of PLs (Table 3). All the 10(100\%) PLs reported that their confidence, communication, presentation and teaching skills had improved through the PAL project; 9(90\%) agreed that their leadership and management skills, as well as their ability to adapt to a particular audience, had improved; and 9(90\%) also reported improvement in other skills, such as teamwork, the ability to work under pressure and professionalism.

\section{Discussion}

In line with other studies, the current study also found PAL to be beneficial. This implies that there are certain areas of curriculum that can be taught more effectively by PLs. Students led by PLs performed better compared to those taught by trained LTs, which is similar to a study in which PLns outperformed their staff-taught counterparts, ${ }^{3}$ but in contrast with other studies which showed no significant improvement. ${ }^{14,17}$

We observed that PLns found PLs much less authoritative in their style of teaching compared to professional staff, as has been reported previously. ${ }^{18}$ Prior research also shows that PLns feel more confident about the material being taught by PLs, since they feel that if the PLs could manage to master it, they would be able to do that as well. ${ }^{5}$ Since the PLns were relatively more comfortable with their PLs, they did not hesitate in going back to them to ask for constructive evaluation regarding their own performance in the PAL session, and, thus, improved their knowledge and skills. The finding is also supported by literature. 7,18 PLns also felt that PLs brought a handy and unique perspective to whatever material they were teaching, making it more applicable and appropriate to their level. ${ }^{5}$ In addition, PLns felt that PLs, besides imparting academic material, also provided valuable advice about coping and dealing with medical school, the tricks of the trade, and, so to speak, the "hidden curriculum".9

PAL sessions in the current study had many benefits for the PLs themselves, related to both academics and personality development. Previous researches have reported widely that the experience of being a $\mathrm{PL}$, and teaching material to students leads to the PLs themselves mastering that very material; 17 a benefit that would lead to better academic performance by the PLs. Higher levels of confidence and better communication skills are tremendous advantages to practising physicians in their professional lives $8,13,19$ and the results of the current study showed vast improvements in confidence and communication skills of the PLs.

The skill of teaching is one of paramount importance when students enter their professional medical career.9,13,19 All PLs in this study reported to have experienced an improvement in their presentation and teaching skills. Teaching skills will prove useful in scenarios where doctors have to explain situations or material to patients, residents, 
or even students, should they be involved in lecturing or teaching. It is important that the art of teaching be inculcated in medical students during their undergraduate years to best equip them for the future. ${ }^{20}$ Studies have also identified PAL as a strong way of inculcating leadership and teamwork skills within students. ${ }^{14}$ The current study also had similar results, with PLs reporting that their leadership and management skills had benefited from PAL. This is indeed a sizeable benefit of PAL, as when students graduate from medical school, they can contribute strong leadership and management aptitude to the healthcare delivery system. Lastly, in PAL ventures where the PLs are paid a stipend, there is a handy opportunity for the PLs to get a feel of professional paid work. Studies also report PLs feeling a sense of altruistic satisfaction in helping their peers becoming better doctors. ${ }^{9}$

The current study also noted a few shortcomings that could be associated with the use of PAL as a formal educational tool in higher education. To begin with, the time invested in training PLs to master the curriculum content was considerable, amounting to around 8 hours of preparation needed for the 2-hour sessions. And yet there is always the undeniable fact that however well-trained PLs are, they cannot quite match up to the knowledge of an experienced professional.

In terms of limitations, there was a selection bias in the division between PLns and LT-led students, as this was not done randomly but on the basis of the students choosing themselves to become a PLn or not. There could also be the possibility of disciplinary issues arising on the part of the PLns, since the PLs were of their own age, rather than senior teachers. This could lead to PLs being pressurised during PAL sessions, causing subsequent decline in their teaching.

Furthermore, there was a lack of a definitive outcome measure to compare the results of PLns and LT-led students. The MCQ test used to compare was formative, leaving chances that some students might not have been serious while attempting it. To add to this, one PAL lab session is insufficient to draw concrete conclusions about PALs effectiveness, especially as the sample size was relatively small. Lastly, this study only evaluated PAL's potency in laboratory sessions for practical skills and did not explore its effectiveness in the purely theoretical teaching setting of a lecture.

The study is also limited since the sample was not representative of the general population; hence it was not possible to infer that other PLns would have the same gains. The trained LTs are always given routine briefings about the lab and they perform "pre-run" of all experiments, yet they cannot represent all trained LTs in other medical schools. Calculation of sample size for the PLs and PLns was done according to any formula. The current study was a pilot study and selected the PIns according to its own selection criteria. The findings of the study need to be validated through further and larger studies. Despite the limitations, the study is important as it has determined the strong utility of PAL over a broader range of topics and what issues are encountered in disseminating it across all courses. The steps undertaken for its implementations can revolutionise teaching.

\section{Conclusion}

PAL was found to be a handy tool for maximising student learning during lab sessions for first year medical students. It facilitated academic growth, initiated professional development, gave economic benefits and inculcated communication and leadership skills in PLs to emerge as future leaders in the health industry.

\section{Disclaimer: None.}

Conflicting interests: None.

Source of Funding: AKU Scholarship of Teaching and Learning (SoTL Grant).

\section{References}

1. Rehman R, Razi MS, Syed S, Sultan T. Impact of alterations in teaching methodologies on learning capabilities. J Pak Med Assoc 2011; 61: 982-5.

2. Topping KJ. The effectiveness of peer tutoring in further and higher education: A typology and review of the literature. High Educ 1996; 32: 321-45.

3. Herrmann-Werner A, Gramer R, Erschens R, Nikendei C, Wosnik A, Griewatz J, et al. Peer-assisted learning (PAL) in undergraduate medical education: An overview. Z Evid Fortbild Qual Gesundhwes 2017; 121: 74-81.

4. Ten Cate O, Durning S. Peer teaching in medical education: twelve reasons to move from theory to practice. Med Teach 2007; 29: 591 9.

5. Glynn LG, MacFarlane A, Kelly M, Cantillon P, Murphy AW. Helping each other to learn-a process evaluation of peer assisted learning. BMC Med Educ 2006; 6: 18.

6. Hill E, Liuzzi F, Giles J. Peer-assisted learning from three perspectives: student, tutor and co-ordinator. Clin Teach 2010; 7: 244-6.

7. Tai JHM, Canny BJ, Haines TP, Molloy EK. The role of peer-assisted learning in building evaluative judgement: opportunities in clinical medical education. Adv Health Sci Educ 2016; 21: 659-76.

8. Burgess A, Dornan T, Clarke AJ, Menezes A, Mellis C. Peer tutoring in a medical school: perceptions of tutors and tutees. BMC Med Educ 2016; 16: 85.

9. Ten Cate O, Durning S. Dimensions and psychology of peer teaching in medical education. Med Teach 2007; 29: 546-52.

10. Field M, Burke J, Lloyd D, McAllister D. Peer-assisted learning in clinical examination. Lancet 2004; 363: 490-1.

11. AbdelSalam M, El Tantawi M, Al-Ansari A, AlAgl A, Al-Harbi F. Informal Peer-Assisted Learning Groups Did Not Lead to Better Performance of Saudi Dental Students. Med Princ Pract 2017; 26: 337-42.

12. Hayat $F$. The use of peer-assisted learning in medical education. Med Teach 2012; 34: 258. 
13. Yu T-C, Wilson NC, Singh PP, Lemanu DP, Hawken SJ, Hill AG. Medical students-as-teachers: a systematic review of peer-assisted teaching during medical school. Adv Med Edu Pract 2011; 2: 157-72.

14. Manzoor I. Peer assisted versus expert assisted learning: a comparison of effectiveness in terms of academic scores. J Coll Physicians Surg Pak 2014;24:825-9.

15. Blohm M, Lauter J, Branchereau S, Krautter M, Köhl-Hackert N, Jünger J, et al. "Peer-Assisted Learning" (PAL) in the Skills-Lab-an inventory at the medical faculties of the Federal Republic of Germany. GMS Z Med Ausbild 2015; 32(1).

16. Rehman R, Siddiqi HS, Alam F. Peer leader selection: A step forward for assisted peer learning at Aga Khan University. J Pak Med Assoc 2018; 68: 936-8.
17. Bene KL, Bergus G. When learners become teachers. Fam Med 2014; 46: 783-87.

18. Menezes A, Burgess A, Clarke AJ, Mellis C. Peer-assisted learning in medical school: tutees' perspective. Adv Med Edu Pract 2016; 7: 31 8.

19. Dandavino M, Snell L, Wiseman J. Why medical students should learn how to teach. Med Teach 2007; 29: 558-65.

20. Durning SJ, Ten Cate OTJ. Peer teaching in medical education. Med Teach 2007; 29: 523-24 